\title{
Analysis of modern technologies for improving performance characteristics of cutting band saws
}

\author{
E. Yu. Balaev \\ Institute of Mechanical Engineering and Automotive \\ Kuban State Technological University \\ Krasnodar, Russia \\ balaev1122@mail.ru
}

\author{
A. E. Litvinov \\ Institute of Mechanical Engineering and Automotive \\ Kuban State Technological University \\ Krasnodar, Russia \\ artstyleone@mail.ru
}

\begin{abstract}
The article describes the structure of technologies for increasing the strength of the cutting part of the saw. The article also presents the results of analysis of existing technologies (metallization and surfacing, welding, doping methods), allowing one to obtain a composite with specified characteristics.

The described technologies are generally characterized by the creation of a composite laminate based on the application of coatings, which, in assessing the performance, introduces an additional criterion for adhesion strength. This, in turn, is the main criterion for the operational performance of the cutting tool.
\end{abstract}

Key words-band saw; surfacing; welding; doping methods; cutting

\section{INTRODUCTION}

Currently, in cutting production (both in small-scale and large-scale production) for cutting of rolled products and pipes from ferrous and non-ferrous metals, metal-cutting band saws are increasingly used. This method of cutting metal, objectively, is the most efficient and productive. Improving the design of machines and the advantages of cutting with a blade cutting tool are the main factors contributing to the growth of the use of such machines in various industries. In the engineering industry, the use of an effective cutting tool (CT), which provides specified parameters of efficiency, productivity, accuracy and quality of cutting, because in the total costs of the cutting process on cut-off machines, the cost of cutting tools is up to forty percent. To date, there is a lack of existing production and development of blade cutting tools for metal cutting machines in the domestic machine tool industry, and the current cut-off equipment works exclusively as an instrument for import production, which makes blanking production vulnerable and dependent. The solution of the problem of increasing the energy efficiency of the cutting process of cutting metal cutting equipment and improving its performance is possible by reducing the cutting load, using original design solutions aimed at developing the cutting tool, and analyzing the geometric and stability parameters of existing tools in the development of new types of cutting tools. This will increase the reliability and accuracy, functional and technological capabilities, the processing capacity of parts, as well as reduce the cost of operation. That will increase the energy efficiency of cut-off equipment, reduce the cost of Russian machinery products and ensure the country's technological safety by introducing competitive import-substituting cutting tools for cutting-off cutting machines. [1,2]

\section{MATERIALS AND EQUIPMENTS}

Modern trends in the creation of parts, products of engineering design are the creation of composite products.

To date, the most popular bimetallic saws with a tooth are made from high-speed steel M42 (analog 11R2M10K8). This steel is characterized by high hardness (HRC 67-68) and heat resistance up to 700 degrees. The basis of the saw is a special spring steel, giving strength and durability. The cutting part is welded to the base by means of an electron beam. It makes it possible to use saws of this design in mass production. For the most difficult cutting conditions are used band saws with carbide teeth when cutting on two-column band saw heavy machines with high productivity. On this machine, it is possible to cut hard-to-work materials such as Inconel, Monel, Hastelloy or cast iron alloys. Saws of this type are used for cutting pieces of solid cross-section with a diameter of at least $100 \mathrm{~mm}$.

Bimetallic saws have a long service life and have a high cutting ability due to special production technology, when a strip of high-speed steel is welded to the base of spring steel with an electron beam (Fig. 1).

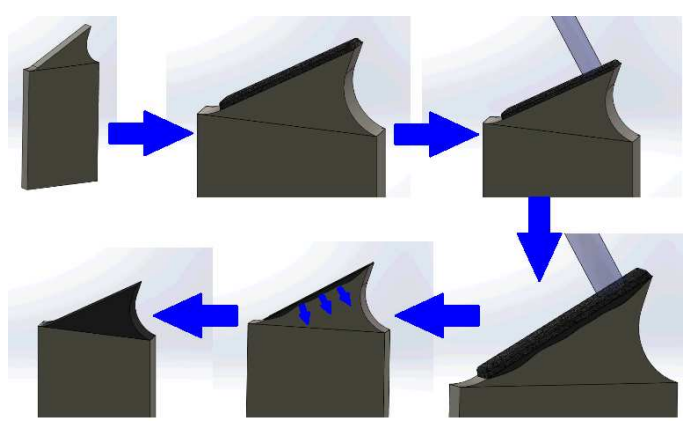

Fig. 1. Manufacturing of bimetallic saws 
Bimetal saws have a constant (normal) or variable (combi) tooth pitch. For cutting hollow profiles, you use a tooth with a variable tooth pitch, although they can also be used for continuous profiles with a slight loss of productivity. The advantage of using a saw with a variable tooth pitch is to reduce noise and vibration, increase durability, improve the quality of the cut. The most universal grade in use as a tooth material is M42. Such saws are used to cut most steels. Stamps M51 and M71, as more wear-resistant, are used for cutting stainless steels and special alloys.

\section{ANALYSIS OF SIMULATION RESULTS AND EXPERIMENTAL DATA.}

As an analogue for the spring-steel saw blade, steel 65 is offered as a material, which is an alternative to the described $\mathrm{m} 42$.

The steel base 65 provides the following advantages to the cutting tool:

1. Good weldability (it is necessary when making saws for a specific machine size).

2. High vibration resistance (ensuring the stability of the cutting process, reducing the drift of the saw during cutting, improving the quality of the cut).

3. Resistance to dynamic and alternating stresses (increased tool life).

The use of steel 65 as a saw cutting material is not possible when processing materials under modern cutting conditions. For the cutting part, it is necessary to use materials with higher physical and mechanical characteristics, which in turn do not meet the requirements for the canvas [3].

The creation of a laminate composite is the main possible alternative for a tool that meets all the necessary requirements.

Among the existing technologies that make it possible to obtain a composite with specified characteristics are methods: metallization and surfacing, welding, alloying methods.

The structure of technologies for increasing the strength of the saw's cutting part is shown in figure 2 .

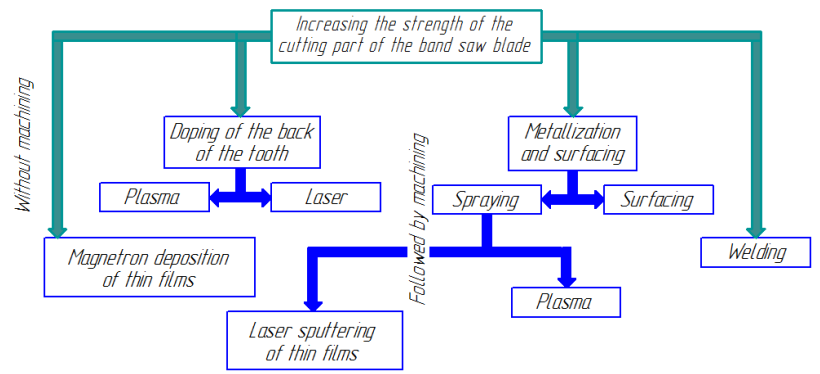

Fig. 2. Technologies for improving the operational characteristics of the saw's cutting part.

Among the technologies of sputtering, the most interesting technologies for today are: detonation spraying, cold gasdynamic spraying and high-speed gas-flame spraying. However, due to the fact that the adhesive strength does not exceed $120 \mathrm{MPa}$. As a result of tool operation, with coatings obtained by this method, the cutting edge is blown from the web at the initial stage of operation $[4,5]$.

Among the existing deposition technologies most suitable for adhesion requirements is the creation of a thin film using laser pulsed deposition and a functional layer using plasma spraying technology [6,7].

Of these two technologies, laser pulsed deposition technology is the most preferable, since, in contrast to plasma spraying, there is no need for subsequent machining [7].

The technology of surfacing is not applicable, as a result of uneven heating throughout the plane of the saw blade with uneven cooling, which results in high residual stresses and subsequent warping, which is unacceptable for a cutting tool of this type.

The welding technology also has drawbacks for this type of tool, since it also requires the removal of residual stresses and subsequent machining. In addition, a significant limitation is imposed by the selection of the material by the criterion of weldability [3].

Magnetron-ion deposition is characterized by very high energy costs, in addition, this method is inferior to other technologies for the period of operation, because it allows to receive as a coating only thin films [8].

The described technologies are generally characterized by the creation of a composite laminate based on the application of coatings, which, in assessing the performance, introduces an additional criterion for adhesion strength. This, in turn, is the main criterion for the operational performance of the cutting tool.

The most effective technology, which allows one to increase the characteristics of the cutting part of the tool, is alloying.

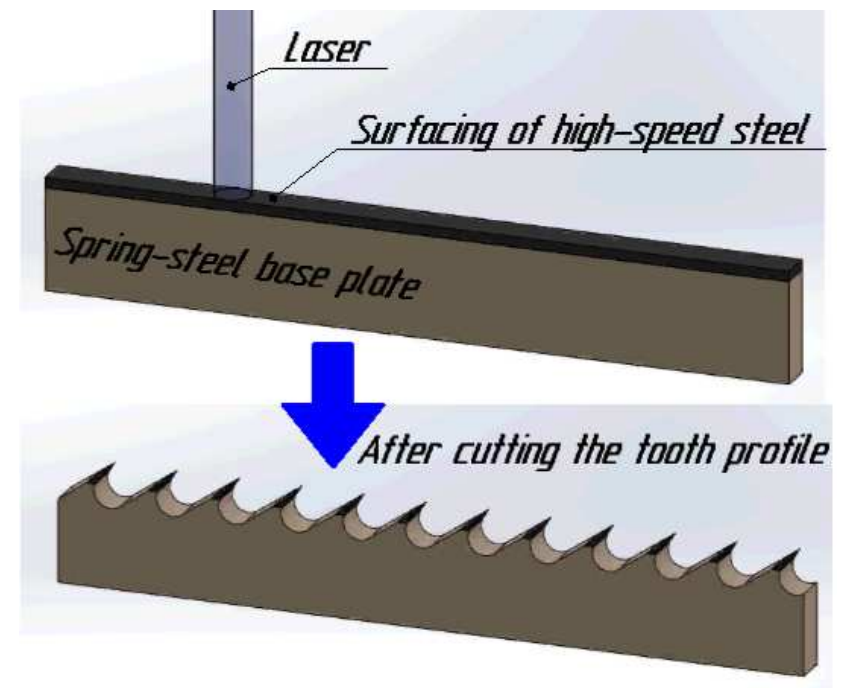

Fig. 3. Production of bimetallic cutting tools using laser welding technology

With reference to band saws, the source of doping will be laser doping along the back surface and plasma doping. 


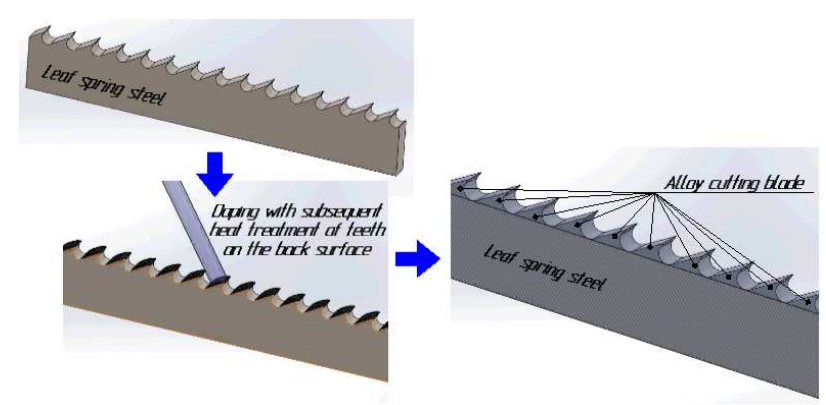

Fig. 4. Scheme of zonal doping using high-energy technologies

Analysis of working conditions of the cutting tool of band saws has shown that saws undergo a complex loading. Thus, during operation, the band saw blade works on bending along three planes, twisting occurs along the center of mass of the saw blade, which allows one to conclude that the saw is complexly fatigued. In addition, during cutting, the teeth of the cutting portion of the saw are also subjected to alternating stress and operate under friction conditions, the cutting process being accompanied by an increase in the temperature in the cutting zone, which leads to heating of the material being processed and the cutting tool itself. Thus, this leads to the fact that the saw blade also works on friction. In the process of cutting, the saw also experiences vibrational loads, and the teeth of the cutting part can experience shock loading. Due to the heterogeneity of the material being processed, the saws of the belt-cutting machines also often experience temporary overloads. The saw loading patterns are shown in Figure 5-7 [1-4].

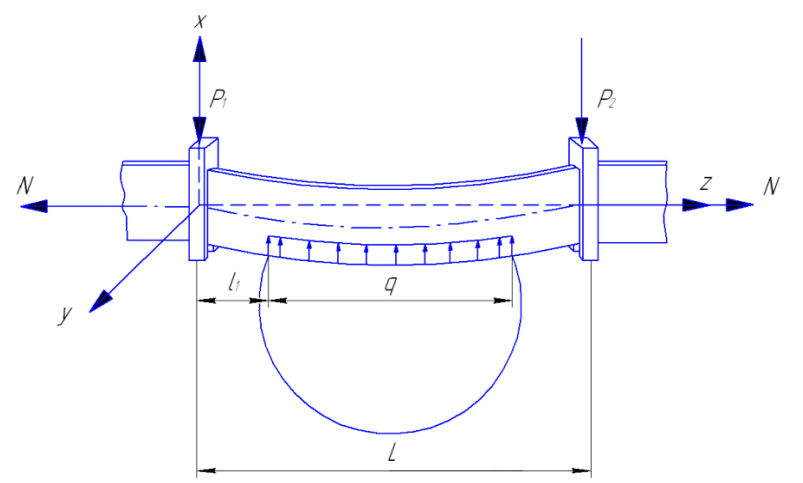

Fig. 5. The scheme of loading of a saw in a vertical plane:

L - section of the saw between the guides; 1 - cutting line; $\mathrm{q}$ - distributed vertical load, constant in magnitude along the cutting line; s - pitch of the saw; $\mathrm{z}^{-}$along the saw, yperpendicular to the plane of the saw, $x$ - in the plane of the saw perpendicular to the $\mathrm{z}$ axis; $\mathrm{P}_{1}$ and $\mathrm{P}_{2}$ - vertical forces arising in the guides as a result of the distributed load;

$\mathrm{N}$ - the tensile force.

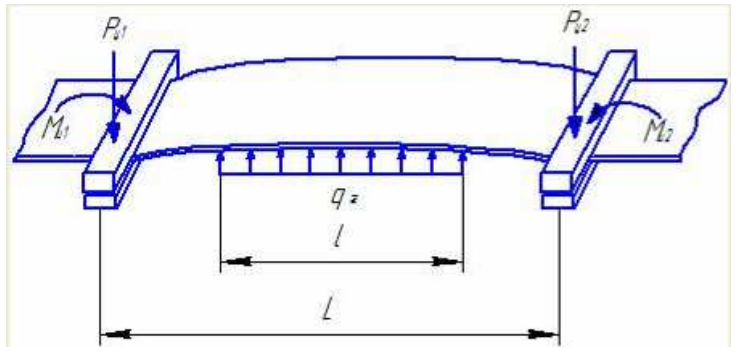

Fig. 6. The scheme of loading the saw in the horizontal plane:

$\mathrm{q}_{\mathrm{z}}$ - a small horizontal component of the distributed cutting force, acting on the saw teeth; $\mathrm{P}_{\mathrm{y} 1}, \mathrm{P}_{\mathrm{y} 2}$ - reaction forces; $\mathrm{M}_{\mathrm{u} 1}, \mathrm{M}_{\mathrm{u} 2^{-}}$moments of reactions.

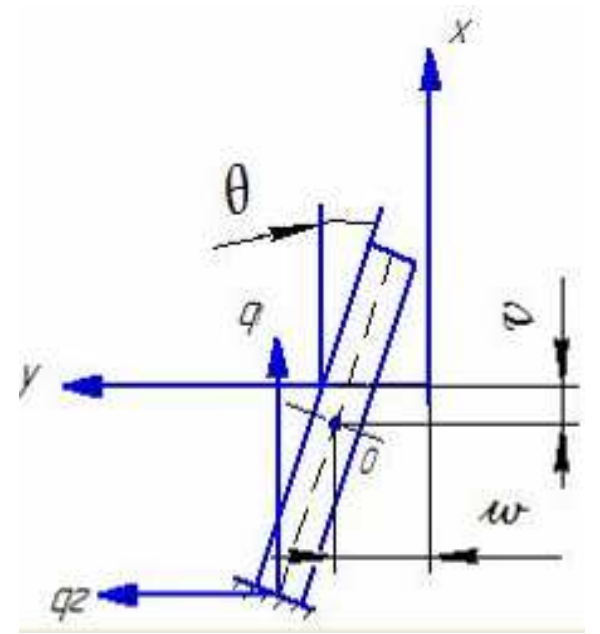

Fig. 7. Torsional loading of the saw

The analysis of the working conditions of the saw was carried out both experimentally and on the ANSYS software complex (shown in Fig. 8-12).

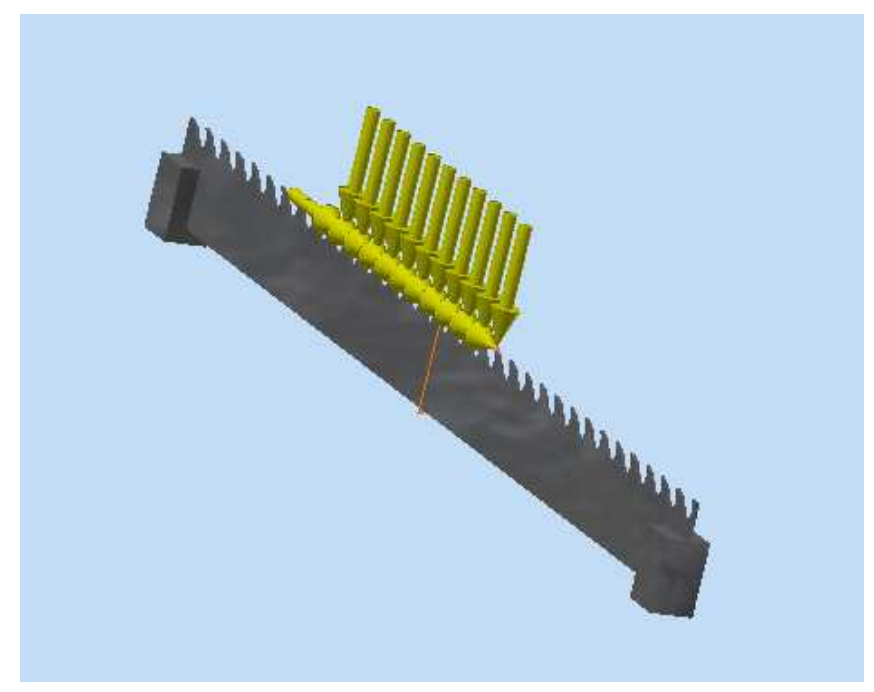

Fig. 8. Simulation of loading 


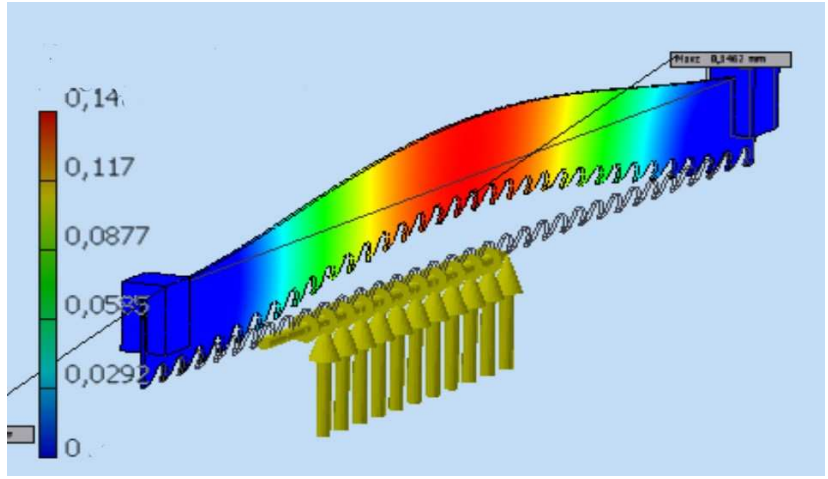

Fig. 9. Results of simulation of loading

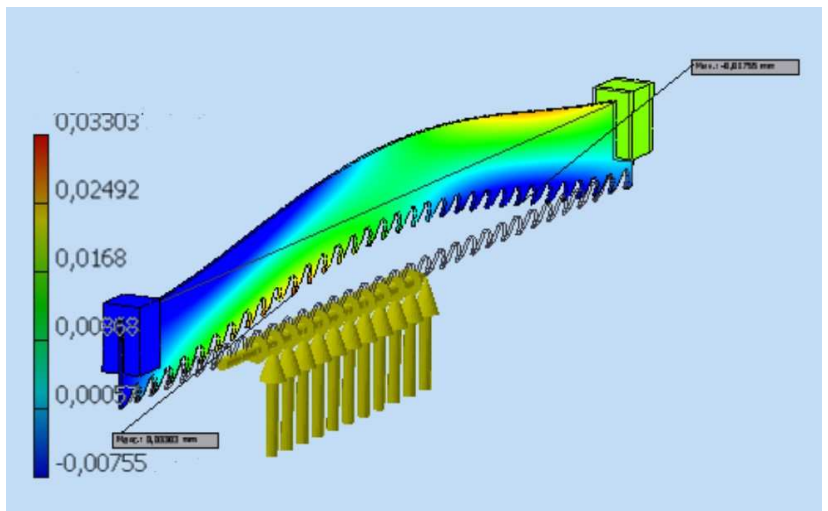

Fig. 10. Results of simulation of loading. The coordinate shift $\mathrm{x}$

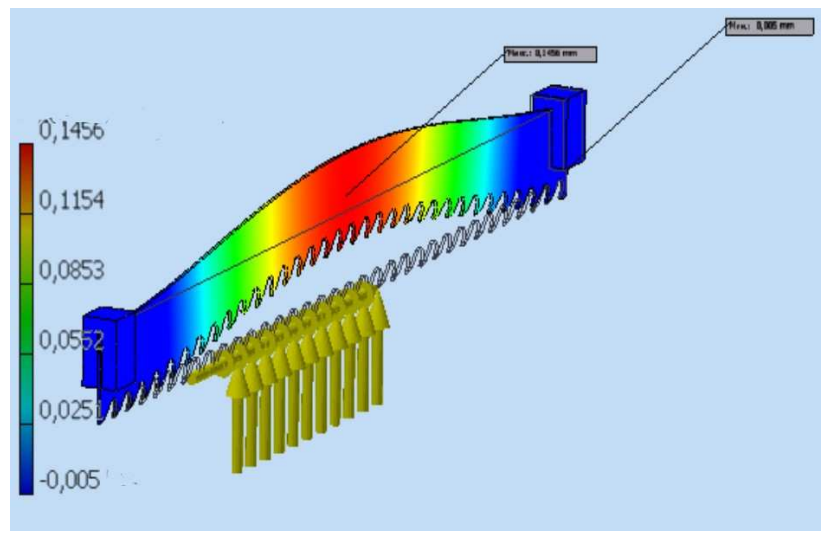

Fig. 11. Results of simulation of loading. The coordinate shift y

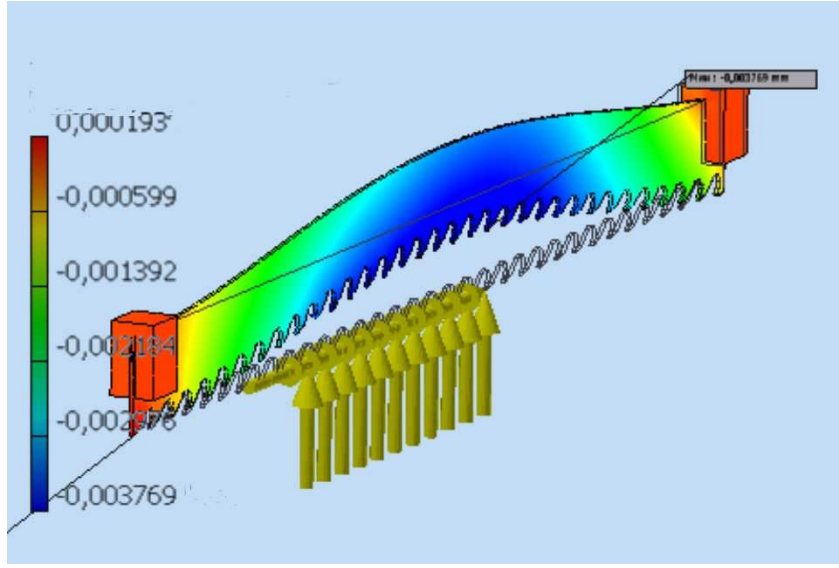

Fig. 12. Results of simulation of loading. Coordinate offset $\mathrm{z}$

According to the data obtained, it was concluded that the most vulnerable point of the band saw is the place where the web is welded into the ring, since the welds do not work well for the alternating load. However, the alternative does not exist today, because according to the requirements of manufacturability and the place of the joint should not have protrusions of linings, etc. Therefore, to reduce the sensitivity to the alternating loads of this section of the band saw, various methods of thermal or thermomechanical processing are used to normalize the structure in the weld seam and the weld zones. In addition, this makes it possible to reduce the residual stresses arising after welding as a result of the difference in material structures due to the different heating temperatures of the material as they move away from the weld, which can correspond to the quenching, tempering, annealing, etc. temperatures. Due to the difference in the requirements for the physical and mechanical properties of the saw blade and cutting part of the saw, it becomes necessary to produce a saw having a composite structure that would allow a saw that satisfies all conditions imposed on both the web and the cutting part. The manufacture of a saw from a single material, both for the cutting part and for the web with subsequent thermal and thermomechanical treatment, does not give a saw that meets the requirements for modern cutting tools. Thus, the alternative was the manufacture of a bimetallic saw, which would consist of two materials - one of which is used for fabrication of the web, and the other is welded using laser welding to the web and used as the material of the teeth of the saw's cutting part. However, in addition to the limitations on weldability of materials, there is a limitation in technology, because as a result of the complex loading, as well as the effect of temperature on the saw, as a result of the saw's friction against the workpiece, the place of welding of the web and cutting part is also a vulnerable point. An alternative solution for creating a bimetallic composite for saws can be the technology of creating coatings on the saw's cutting part from special materials. However, existing technologies that make it possible to obtain such coatings also have disadvantages. As a disadvantage, one can note a low adhesion or a small thickness of such coating. Thus, the most suitable technology for creating a bimetallic composite for a saw from a single material is the technology of local doping, which makes it possible to make a saw from a material that satisfies the material of the saw blade according to its physico- 
mechanical characteristics. As a rule, spring-steel steels are used for this purpose, among which there is steel 65, which, in addition to its resistance to alternating loads, also has high vibration resistance.

\section{CONCLUSION}

The resulting during operation, the vibration of the tool adversely affects not only the operation of the equipment itself, the service life, the accuracy of processing, etc., but also the resistance of the instrument itself, since the vibrations can be referred to the form of variable loads varying with time at a high frequency, turn accelerates the process of fatigue failure of the tool [9]. Also, vibrations can accelerate the propagation of cracks in the tool and facilitate the accumulation of dislocations with the formation of microcracks and their further growth. During vibration, the tool also heats up and, as is known, the physical and mechanical properties of the material change with increasing temperature. All this indicates the need to avoid the occurrence of vibration in the instrument, additionally introducing vibration damping systems, and in cases where vibration resistant materials cannot be avoided [9, $10]$.

For the manufacture of band saw blades, the materials used in springs and springs, which are capable of absorbing and quenching the arising oscillations, are applied as rules, however, the use of these materials for the cutting part of the tool is not acceptable, since such materials do not have sufficient characteristics for the cutting part of the tool [3].

In the future, local doping of the cutting part of the saw with subsequent thermal and thermomechanical processing should be carried out, thus it will be possible to obtain a cutting part meeting all the requirements for a modern cutting tool in terms of its characteristics. In turn, the application of the technology of local doping allows it to be carried out, thanks to unique features, like a pre-sweep, which in turn will enable to carry out rough processing of the material with lower physical and technological properties, which will facilitate the process of making the saw, and, as a result, make it more technologically process for the production of band saws.

\section{Acknowledgment}

The work was supported by the Council on grants of the President of the Russian Federation (Agreement No. MK6201.2018.8)

\section{References}

[1] S.V. Kiselev, A.V. Blakhin, A.F. Dulevich, "Band saws with high durability”. Bulletin of BSTU, Vol. 4, pp. 24-27, April 2007.

[2] A.E. Litvinov, "Improving tool life and machining precision in band saws". Russian Engineering Research, Vol. 36, pp. 760-761, 2016. DOI: $10.3103 / \mathrm{S} 1068798 X 16090124$

[3] Z.M. Blednova, P.O. Rusinov, E.U. Balaev, "Quantification of hereditary regularities of surface layer formation and transformation made of multicomponent shape memory materials in a high-energy impact" Materials Today: Proceedings, pp. 4652-4657, 2017, DOI: 10.1016/j.matpr.2017.04.046

[4] L.X. Baldaev, V. Borisov, Gas thermal spraying. Textbook, 2007, p. 344.

[5] A. Hasui, O. Morigaki, Surfacing and spraying, Mechanical. Moskow, 1985 , p. 240

[6] G.P. Laskin, A.P. Kuznechov, "Simulation of ion-plasma doping process". Bulletin of TumSU, Vol. 6, pp. 64-67, 2010.

[7] V.A. Putilin, A.V. Kamashev, A.V. Putilin, "Alloyng of surface of metals under application of short palse laser," Mechanical engineering, 2016, p. 344.

[8] M.K. Gusejnov, M.K. Kurbanov, B.A. Bilalov, G.K. Safaraliev, "Magnetron deposition of thin films of solid solution (SiC)1-x(AlN)x," Physics and technology of semiconductors, Vol 44, pp. 841-844, 2010.

[9] E.V. Rublevskaja, P.A. Komarova., A.V. Shcherbakova, T.D. Husnutdinov, E.V. Ramenskaja, "Analysis of parameters of cutting process by band saws," Actual problems of aviation and cosmonautics, Vol. 1, pp. 35-36, 2017.

[10] V.P. Astahkov, Tribology of metal cutting, pp. 419, 2016. 